\title{
Enhancement of Power System Dynamics through STATCOM
}

\author{
Narendra Kumar ${ }^{1}$ and Vipin Jain ${ }^{2, *}$ \\ ${ }^{1}$ Professor, Electrical Engineering Department, Delhi Technological University, Delhi, India \\ ${ }^{2}$ Assistant Professor, Electrical Engineering Department, Bharat Institute of Technology, Meerut (UP), India \\ Corresponding author
}

\begin{abstract}
In FACTS devices auxiliary signals are widely used to enhance damping and mitigation of Subsynchronous Resonance in Power System. Choice of auxiliary signals is indeed a difficult choice. In this paper STATCOM is installed in the middle of Power system and it is shown that computed generator internal frequency is a very suitable auxiliary signal. Study system is IEEE first benchmark model. Modeling of STATCOM with IEEE first benchmark model is presented in detail. All the differential equations and initial conditions are presented in the paper. Results are shown at $\mathbf{5 0 \%}$ series compensation.
\end{abstract}

Keywords-STATCOM; supplementary signals; power system stability; IEEE first benchmark model

\section{INTRODUCTION}

A Static Synchronous Compensator (STATCOM) is also known as an advanced static VAR compensator. It is capable of generating or absorbing reactive power. STATCOM is a shunt connected device and used to control the transmission line voltage but when auxiliary signal is used as a feedback signal then it can enhance the damping of the system. In STATCOM, type ' 1 ' or type '2' voltage source converters (VSC) can be used. In type ' 1 ' converters both $\mathrm{K}_{\mathrm{cs}}$ and ' $\alpha$ ' are controlled and a DC battery is provided in parallel with capacitor. In type ' 2 ' converters ' $\alpha$ ' can be controlled and ' $\mathrm{K}_{\mathrm{cs}}$ ' is kept fixed. ' $\alpha$ ' alone can control Magnitude and angle of $E_{s}$, voltage across DC side capacitor, active power consumed by the STATCOM and reactive power consumed (or supplied) by the STATCOM [1-4]. In FACTS devices, auxiliary signals (supplementary signals) are widely used to enhance the damping of the power system. The main purpose of auxiliary signal (AS) is to enhance the damping of generator-turbine system [5-6], because the line dynamics are much faster then generator dynamics. In the literature no major efforts are reported to develop a suitable AS for the STATCOM located away from generator end. In this paper STATCOM is installed in the middle of TL and with the signals available at STATCOM bus, derivative of generator rotor angle is computed and it is shown that it can damp all the modes of turbine- generator set. Derivative of generator rotor angle has resemblance with deviation in generator rotor speed $\left(\omega-\omega_{\mathrm{s}}\right)$. In the literature, various auxiliary signals has been tested for TCR-FC (Thyristor controlled reactor with fixed capacitor), where TCR-FC is located in the middle of transmission line.

It is found that generator end frequency computed through local signals, available at TCR-FC bus, is one of the most suitable AS

\section{STUDY SYSTEM}

Study system is IEEE First Benchmark model (FBM) [7]. In the present case STATCOM is installed in the middle of transmission line. Hence all values shown in Figure I can be easily understood. In reference [8] STATCOM is installed at generator end, and all the system differential equations are given in this paper. In present paper STATCOM is in middle of TL hence TL differential equations are changed which are given here:

First Half Transmission Line Equations are

$$
\begin{gathered}
\mathrm{V}_{1 \mathrm{D}}-\mathrm{V}_{2 \mathrm{D}}=\mathrm{R}_{1} \mathrm{I}_{\mathrm{D}}-\omega \mathrm{X}_{1} \mathrm{I}_{\mathrm{Q}}+\frac{\mathrm{X}_{1}}{\omega_{0}} \dot{\mathrm{I}}_{\mathrm{D}} \\
\text { or, } \mathrm{V}_{1 \mathrm{D}}=\mathrm{V}_{2 \mathrm{D}}+\mathrm{R}_{1} \mathrm{I}_{\mathrm{D}}-\omega \mathrm{X}_{1} \mathrm{I}_{\mathrm{Q}}+\frac{\mathrm{X}_{1}}{\omega_{0}} \dot{\mathrm{I}}_{\mathrm{D}} \\
\text { similarly, } \mathrm{V}_{1 \mathrm{Q}}=\mathrm{V}_{2 \mathrm{Q}}+\mathrm{R}_{1} \mathrm{I}_{\mathrm{Q}}+\omega \mathrm{X}_{1} \mathrm{I}_{\mathrm{D}}+\frac{\mathrm{X}_{1}}{\omega_{0}} \dot{\mathrm{I}}_{\mathrm{Q}}
\end{gathered}
$$

Second Half Transmission Line Equations are

$$
\begin{aligned}
& \mathrm{V}_{2 \mathrm{D}}=\mathrm{V}_{3 \mathrm{D}}+\mathrm{V}_{\mathrm{cD}}+\mathrm{R}_{2}\left(\mathrm{I}_{\mathrm{D}}+\mathrm{I}_{\mathrm{sD}}\right)-\omega \mathrm{X}_{2}\left(\mathrm{I}_{\mathrm{Q}}+\mathrm{I}_{\mathrm{sQ}}\right)+\frac{\mathrm{X}_{2}}{\omega_{0}}\left(\mathrm{I}_{\mathrm{C}}+\mathrm{I}_{\mathrm{CD}}\right)(3) \\
& \mathrm{V}_{2 \mathrm{Q}}=\mathrm{V}_{3 \mathrm{Q}}+\mathrm{V}_{\mathrm{cQ}}+\mathrm{R}_{2}\left(\mathrm{I}_{\mathrm{Q}}+\mathrm{I}_{\mathrm{sQ}}\right)+\omega \mathrm{X}_{2}\left(\mathrm{I}_{\mathrm{D}}+\mathrm{I}_{\mathrm{sD}}\right)+\frac{\mathrm{X}_{2}}{\omega_{0}}\left(\mathrm{I}_{\mathrm{Q}}+\mathrm{I}_{\mathrm{sQ}}\right)(4)
\end{aligned}
$$

$I_{D}$ and $I_{Q}$ are current in first half of TL. In [8], Generator equations are presented in $\mathrm{d}-\mathrm{q}$ frame while STATCOM equations, TL equations are presented in D-Q frame. Generator equivalent circuit is shown in Figure III-IV. Generator has three damper windings, one is at d-axis and two are at q-axis. $X_{1}$ is leakage reactance of generator and $R_{a}$ is its armature winding resistance. $\mathrm{I}_{1 \mathrm{~d}}, \mathrm{I}_{1 \mathrm{q}}$, and $\mathrm{I}_{2 \mathrm{q}}$ are the damper winding currents and $\mathrm{I}_{\mathrm{f}}$ is field winding current. In steady state damper winding currents are zero. D-Q axes present network reference frame and $\mathrm{d}-\mathrm{q}$ axes present machine reference frame as shown in Figure V. D-Q axes frame and $d-q$ axes frame both are rotating at synchronous speed. In transient period, speed of D-Q reference frame remains constant but speed of dq frame oscillates, hence rotor angle ' $\delta$ ' oscillates. 


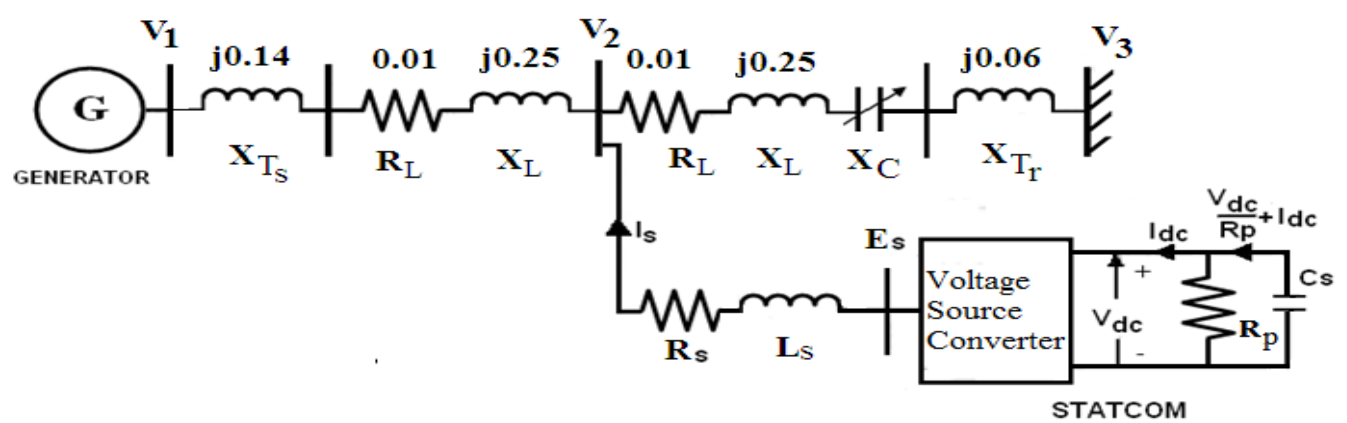

FIGURE I. STUDY SYSTEM

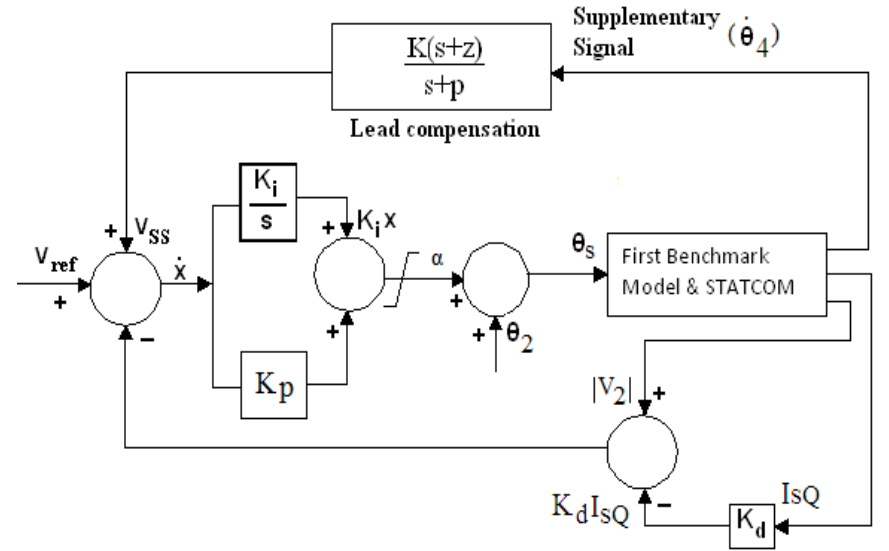

FIGURE II. BLOCK DIAGRAM OF THE SYSTEM

\section{AUXILIARY CONTROLlER DESIGN}

In references [8] it is shown that speed deviation of generator rotor is a very suitable auxiliary signal. Hence in this research derivative of rotor angle is derived with the signals available at bus $V_{2}$. For computation of $\delta$ at bus $V_{2}$, four signals are needed to be measured, these are $\mathrm{V}_{2 \mathrm{D}}, \mathrm{V}_{2 \mathrm{Q}}, \mathrm{I}_{\mathrm{D}}, \mathrm{I}_{\mathrm{Q}}$. Impedance of first half of TL and generator reactances should be known. In actual system $\mathrm{V}_{2 \mathrm{D}}, \mathrm{V}_{2 \mathrm{Q}}, \mathrm{I}_{\mathrm{D}}$, $\mathrm{I}_{\mathrm{Q}}$ can be measured but for simulation purpose two signals $\mathrm{I}_{\mathrm{D}}, \mathrm{I}_{\mathrm{Q}}$ are available and $\mathrm{V}_{2 \mathrm{D}}, \mathrm{V}_{2 \mathrm{Q}}$ are not available because $\mathrm{V}_{2 \mathrm{D}}$ and $\mathrm{V}_{2 \mathrm{Q}}$ are not state variables, so $\mathrm{V}_{2 \mathrm{~B}}$ and $\mathrm{V}_{2 \mathrm{Q}}$ are derived as follows

$$
\begin{aligned}
& \mathrm{V}_{2 \mathrm{D}}=\mathrm{V}_{3 \mathrm{D}}+\mathrm{V}_{\mathrm{cD}}+\mathrm{R}_{2}\left(\mathrm{I}_{\mathrm{D}}+\mathrm{I}_{\mathrm{sD}}\right)-\omega \mathrm{X}_{2}\left(\mathrm{I}_{\mathrm{Q}}+\mathrm{I}_{\mathrm{sQ}}\right) \\
& \mathrm{V}_{2 \mathrm{Q}}=\mathrm{V}_{3 \mathrm{Q}}+\mathrm{V}_{\mathrm{cQ}}+\mathrm{R}_{2}\left(\mathrm{I}_{\mathrm{Q}}+\mathrm{I}_{\mathrm{sQ}}\right)+\omega \mathrm{X}_{2}\left(\mathrm{I}_{\mathrm{D}}+\mathrm{I}_{\mathrm{sD}}\right)
\end{aligned}
$$

Therefore $\dot{\mathrm{V}}_{2 \mathrm{D}}$ and $\dot{\mathrm{V}}_{2 \mathrm{Q}}$ are obtained as follows:

$$
\begin{aligned}
& \mathrm{V}_{2 \mathrm{D}}^{\text {晻 }}=\mathrm{V}_{\mathrm{cD}}+\mathrm{R}_{2}\left(\mathrm{I}_{\mathrm{D}}^{\text {晻 }}+\mathrm{I}_{\mathrm{sD}}\right)-\omega \mathrm{X}_{2}\left(\mathrm{I}_{\mathrm{Q}}+\mathrm{I}_{\mathrm{SQ}}\right) \\
& \mathrm{V}_{2 \mathrm{Q}}=\mathrm{V}_{\mathrm{cQ}}+\mathrm{R}_{2}\left(\mathrm{~B}_{\mathrm{Q}}+\mathrm{B}_{\mathrm{C}}\right. \\
& \left.\mathrm{I}_{\mathrm{SQ}}\right)+\omega \mathrm{X}_{2}\left(\mathrm{I}_{\mathrm{D}}+\mathrm{I}_{\mathrm{CD}}\right)
\end{aligned}
$$

晻 $\mathrm{I}_{\mathrm{D}}, \mathrm{I}_{\mathrm{Q}}, \mathrm{I}_{\mathrm{SD}}$ and $\mathrm{I}_{\mathrm{SQ}}$ are state variables hence available signals for simulation purpose. Voltage at node $4\left(\mathrm{~V}_{4 \mathrm{D}}\right.$ and $\mathrm{V}_{4 \mathrm{Q}}$ in Figure III-IV) represent voltage generated by generator. In D-Q axes frame, angle of voltage at node $4\left(\theta_{4}\right)$ is almost equal to $\delta$. $\dot{\theta}_{4}$ is derived and used as AS as follows:

$$
\begin{gathered}
\mathrm{V}_{4 \mathrm{D}}=\mathrm{V}_{2 \mathrm{D}}+\mathrm{R}_{1} \mathrm{I}_{\mathrm{D}}-\omega\left(\mathrm{X}_{1}+\mathrm{X}_{l}+\mathrm{X}_{\mathrm{md}}\right) \mathrm{I}_{\mathrm{Q}} \\
\mathrm{V}_{4 \mathrm{Q}}=\mathrm{V}_{2 \mathrm{Q}}+\mathrm{R}_{1} \mathrm{I}_{\mathrm{Q}}+\omega\left(\mathrm{X}_{1}+\mathrm{X}_{l}+\mathrm{X}_{\mathrm{mq}}\right) \mathrm{I}_{\mathrm{D}} \\
\text { or, } \mathrm{V}_{4 \mathrm{D}}=\mathrm{V}_{2 \mathrm{D}}+\mathrm{R}_{1} \text { 晻 }_{\mathrm{D}}-\omega\left(\mathrm{X}_{1}+\mathrm{X}_{l}+\mathrm{X}_{\mathrm{md}}\right) \mathrm{I}_{\mathrm{Q}}
\end{gathered}
$$$$
\text { similarly, } \mathrm{V}_{4 \mathrm{Q}}^{\text {晻 }}=\mathrm{V}_{2 \mathrm{Q}}+\mathrm{R}_{1} \text { 晻 }_{\mathrm{Q}}^{\text {列 }}+\omega\left(\mathrm{X}_{1}+\mathrm{X}_{l}+\mathrm{X}_{\mathrm{mq}}\right) \mathrm{I}_{\mathrm{D}}
$$

$$
\theta_{4}=\tan ^{-1} \frac{\mathrm{V}_{4 \mathrm{Q}}}{\mathrm{V}_{4 \mathrm{D}}} \text { or, } \dot{\theta}_{4}=\frac{\mathrm{V}_{4 \mathrm{D} 0} \mathrm{~V}_{4 \mathrm{Q}}-\mathrm{V}_{4 \mathrm{C} 0} \mathrm{~V}_{4 \mathrm{D}}}{\mathrm{V}_{40}}
$$

Subscript ' 0 ' represents initial conditions. Approximately $\delta=$ $\theta_{4}$ hence $\delta=\theta_{4}$, so $\dot{\theta}_{4}$ is used as AS. In equations 7-8 damper winding currents should be also taken into account but damper windings currents are not available at bus $\mathrm{V}_{2}$ hence not the part of equations 7-8. Approximate steady state value of $\delta$ can be calculated with equations 5-6.

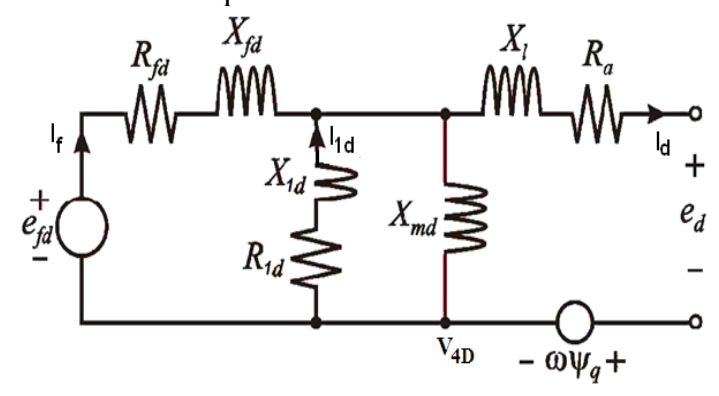

FIGURE III. GENERATOR D-AXIS EQUIVALENT CIRCUIT 


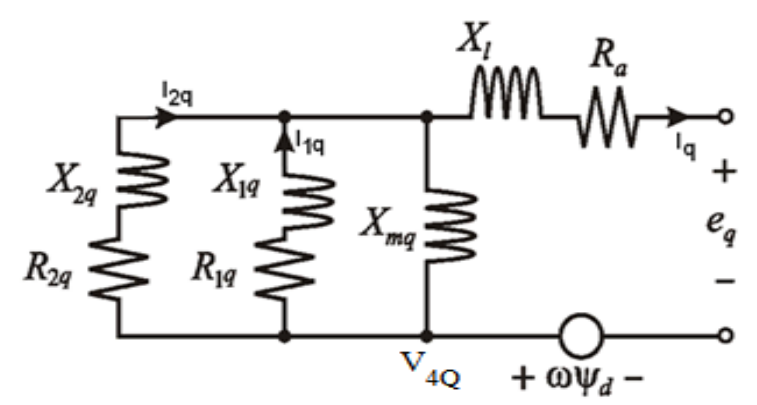

FIGURE IV. GENERATOR Q-AXIS EQUIVALENT CIRCUIT

\section{RESUlTS AND DiscUSSIONS}

Generally SSR problem occurs at high series compensation. Hence results and initial conditions are shown at 50\% series compensation $\left(\mathrm{X}_{\mathrm{c}}=0.25\right)$. Eigenvalues are tabulated in Table 1. Column 2 shows results without STATCOM (i.e. FBM only). Column 3 shows results with STATCOM but without PI controller. In this case, system is as open loop transfer function having input $\alpha$ and output $\left|V_{2}\right|$. In column 4, eigenvalues are with STATCOM and PI controller and thereafter in column 5, eigenvalues are with STATCOM, PI controller and AS. Various Transient responses are shown in Figure VI-XI. Disturbance is sudden thirty percent increase in mechanical torque for a period 0.1 second, after 1 second from the start of simulation. In whole study natural damping is kept zero.

\section{APPENDIX}

Initial Condition of the system at $X_{c}=0.25 \quad(50 \%$ compensation). All quantities are in pu and angles in radians, unless otherwise specified.

- Generator circuit data: $R_{a}=0, \quad X_{l}=0.13, \quad X_{m d}=1.66$, $\mathrm{R}_{1 \mathrm{~d}}=0.00408, \quad \mathrm{X}_{1 \mathrm{~d}}=0.0055, \quad \mathrm{R}_{\mathrm{fd}}=0.001406, \quad \mathrm{X}_{\mathrm{fd}}=0.062$, $\mathrm{X}_{\mathrm{mq}}=1.58, \mathrm{R}_{1 \mathrm{q}}=0.00822, \mathrm{X}_{1 \mathrm{q}}=0.095, \mathrm{R}_{2 \mathrm{q}}=0.01406, \mathrm{X}_{2 \mathrm{q}}=0.326$. Power supplied by generator $\mathrm{P}_{\mathrm{g}}=0.807, \mathrm{PF}=0.823$ (lagging). $\mathrm{V}_{1}=1.097 \angle 0.3566, \mathrm{~V}_{2}=0.936 \angle 0.051, \mathrm{~V}_{3}=0.893 \angle 0 \quad$. In steady state, damper winding currents are zero (i.e. $\mathrm{I}_{1 \mathrm{~d}}=$ $\left.\mathrm{I}_{2 \mathrm{~d}}=\mathrm{I}_{2 \mathrm{q}}=0\right)$. Terminal voltage of generator $\left(\mathrm{V}_{1}\right)$ in $\mathrm{d}-\mathrm{q}$ frame: $\mathrm{e}_{\mathrm{d}}$ $=0.592, \mathrm{e}_{\mathrm{q}}=0.924$ or, $1.097 \angle 1.0015$. It can be found that

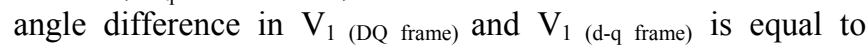
$(\pi / 2)-\delta$. (This can be analyzed from Figure V). Active power consumed by STATCOM $=0.00109$, Reactive power supplied by STATCOM $=0.30508, \mathrm{E}_{\mathrm{s}}=0.9845 \angle 0.047, \alpha=-$ 0.00349 . It can be seen that $E_{s}>V_{2}, \alpha$ is negative therefore STATCOM is in capacitive mode. It is supplying reactive power to the system and consuming small amount of active power to meet out the losses in $\mathrm{R}_{\mathrm{s}}$ and $\mathrm{R}_{\mathrm{p}}$ (transformer losses and switching losses). STATCOM circuit data: $R_{s}=0.01$, $\mathrm{X}_{\mathrm{s}}=0.15, \mathrm{R}_{\mathrm{p}}=125, \mathrm{C}_{\mathrm{s}}=0.5968, \mathrm{~K}_{\mathrm{cs}}=15.59$,

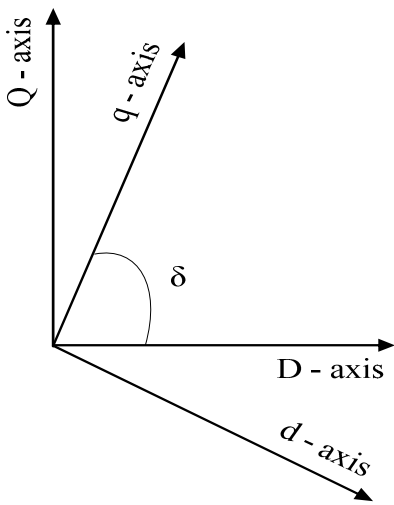

FIGURE V. D-Q AND d-q REFERENCE FRAME

- In all the equations $\omega_{0}=376.99 \mathrm{rad} / \mathrm{sec}$, while $\omega=1 \mathrm{pu}$. In transient period value of $\omega_{0}$ remain same while $\omega$ oscillates. In Mechanical system modeling, in steady state $\omega_{\mathrm{E}}=\omega=\omega_{\mathrm{B}}=$ $\omega_{\mathrm{A}}=\omega_{\mathrm{I}}=\omega_{\mathrm{H}}=\omega_{\mathrm{S}}=1$. In transient period $\omega_{\mathrm{S}}$ remains constant.

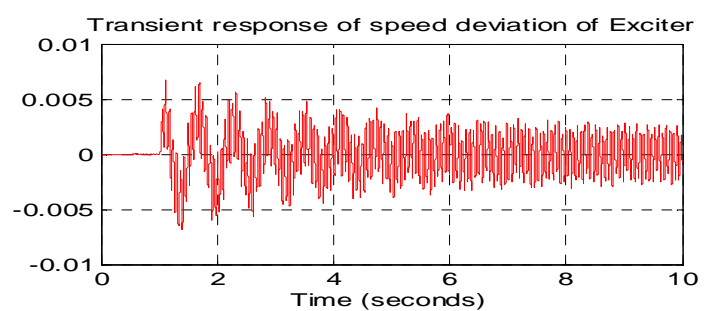

FIGURE VI. RESPONSE OF SPEED DEVIATION OF EXCITER WITH AS

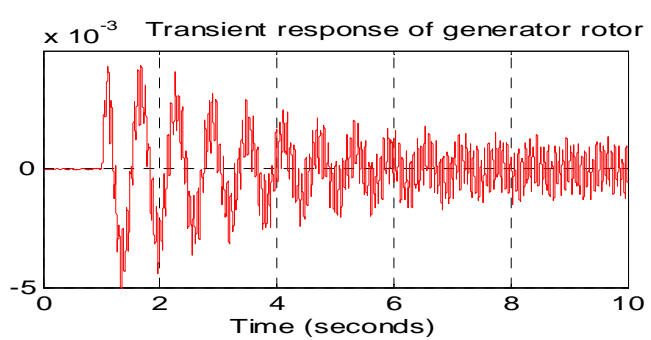

FIGURE VII. RESPONSE OF SPEED DEVIATION OF ROTOR WITH AS

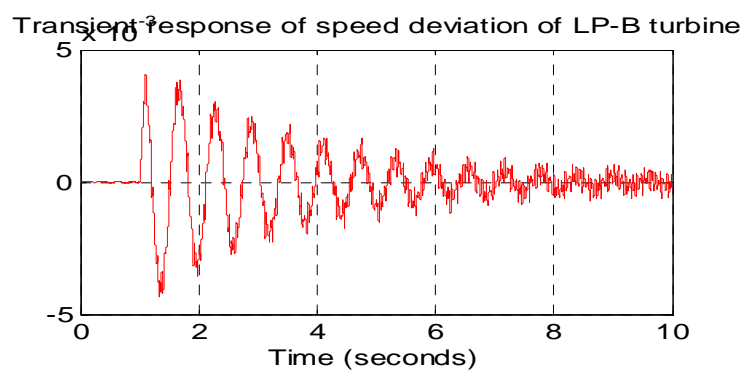

FIGURE VIII. RESPONSE OF SPEED DEVIATION OF LP-B TURBINE WITH AS 


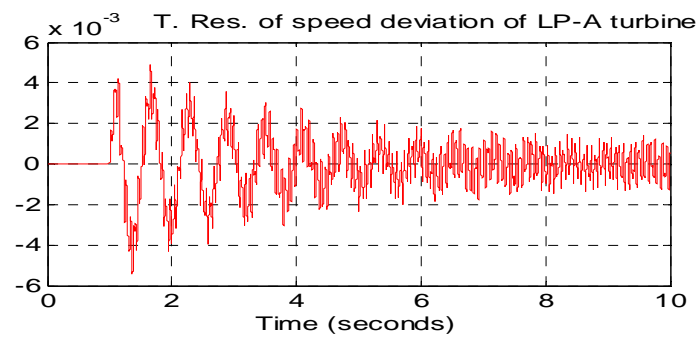

FIGURE IX. RESPONSE OF SPEED DEVIATION OF LP-A TURBINE WITH AS

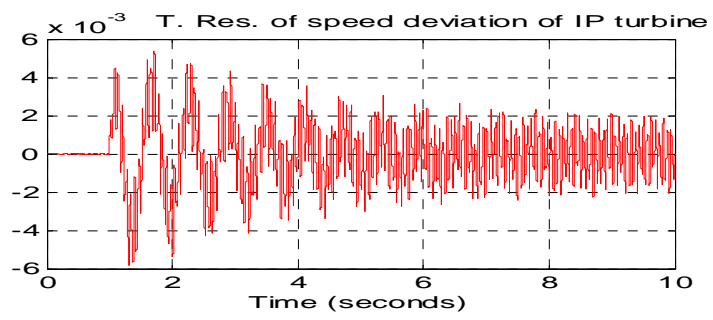

TABLE I. EIGEN VALUES AT 50\% COMPENSATION
FIGURE X. RESPONSE OF SPEED DEVIATION OF IP TURBINE WITH AS

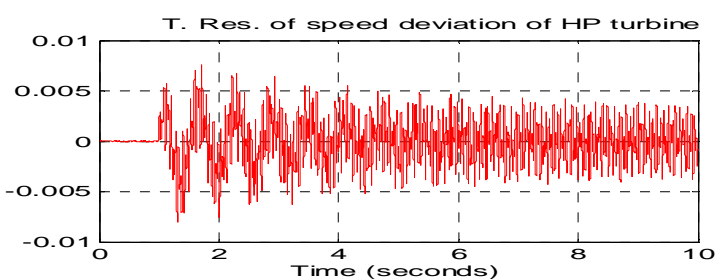

FIGURE XI. RESPONSE OF SPEED DEVIATION OF HP TURBINE WITH AS

\begin{tabular}{|c|c|c|c|c|}
\hline Description & $\begin{array}{c}\text { Eigenvalues of IEEE } \\
\text { First Benchmark Model without } \\
\text { any controller }\end{array}$ & $\begin{array}{c}\text { Eigenvalues with STATCOM } \\
\text { only } \\
\text { (without PI controller and } \\
\text { AS) }\end{array}$ & $\begin{array}{c}\text { Eigenvalues with } \\
\text { STATCOM \& PI } \\
\text { controller but without } \\
\text { AS }\end{array}$ & $\begin{array}{c}\text { Eigenvalues with } \\
\text { STATCOM, PI } \\
\text { controller and AS }\end{array}$ \\
\hline Supersynchronous & $-4.646 \pm 579.54 \mathrm{i}$ & $-3.2291 \pm 547.02 \mathrm{i}$ & $222.32 \pm 554.16 \mathrm{i}$ & $-52.061 \pm 478.62 \mathrm{i}$ \\
\hline Torsional Mode No. 5 & $-5.2871 \mathrm{e}-6 \pm 298.18 \mathrm{i}$ & $1.5109 \mathrm{e}-5 \pm 298.18 \mathrm{i}$ & $9.0137 \mathrm{e}-06 \pm 298.18 \mathrm{i}$ & $-7.7467 \mathrm{e}-06 \pm 298.18 \mathrm{i}$ \\
\hline Torsional Mode No. 4 & $-0.012035 \pm 202.61 \mathrm{i}$ & $1.5319 \pm 203.01 \mathrm{i}$ & $0.026638 \pm 202.79 \mathrm{i}$ & $-0.029263 \pm 202.86 \mathrm{i}$ \\
\hline Torsional Mode No. 3 & $0.17147 \pm 161.03 \mathrm{i}$ & $-0.03525 \pm 160.83 \mathrm{i}$ & $0.021433 \pm 160.43 \mathrm{i}$ & $-0.020023 \pm 160.51 \mathrm{i}$ \\
\hline Torsional Mode No. 2 & $0.0060428 \pm 127.06 \mathrm{i}$ & $-0.008165 \pm 127.06 \mathrm{i}$ & $0.020248 \pm 126.9 \mathrm{i}$ & $-0.0048197 \pm 126.98 \mathrm{i}$ \\
\hline Torsional Mode No. 1 & $0.026771 \pm 99.373 \mathrm{i}$ & $-0.073882 \pm 99.466 \mathrm{i}$ & $1.7288 \pm 101.97 \mathrm{i}$ & $-0.0064684 \pm 98.512 \mathrm{i}$ \\
\hline Subsynchronous & $-3.5423 \pm 173.98 \mathrm{i}$ & $-8.5016 \pm 200.18 \mathrm{i}$ & $-4.1588 \pm 105.73 \mathrm{i}$ & $-10.102 \pm 48.583 \mathrm{i}$ \\
\hline Electromechanical & $-0.56275 \pm 9.3669 \mathrm{i}$ & $-0.48089 \pm 10.701 \mathrm{i}$ & $-0.57262 \pm 10.021 \mathrm{i}$ & $-0.45441 \pm 10.405 \mathrm{i}$ \\
\hline mode & & $-9.2442 \pm 832.95 \mathrm{i}$ & $1.5986 \pm 624.36 \mathrm{i}$ & $-41.667 \pm 869.66 \mathrm{i}$ \\
\hline STATCOM currents & -11.114 & $-229 \pm 545.35 \mathrm{i}$ & $-145.89,-4116.1$ \\
\hline $\mathrm{V}_{\mathrm{dc}} \&$ PI & & & & -24.868 \\
\hline Lead Compensation & -32.685 & -33.002 & -32.721 & -33.276 \\
\hline others & -20.36 & -20.339 & -20.375 & -20.067 \\
\hline
\end{tabular}

\section{REFERENCES}

[1] K. R. Padiyar, "FACTS controllers in power transmission and distribution" New Age International Publishers, 2007.

[2] P. Kundur, "Power system stability and control" McGraw-Hill, New York, USA, 1993.

[3] J. Machowski, J. W. Bialek, J. R. Bumby, "Power system dynamics: stability and control" John Wiley \& Sons, 2008.

[4] S. Sirisukprasert, "The modeling and control of a cascaded multilevel converter based STATCOM" Dissertation, Virginia Polytechnic and state university, USA, 2004.

[5] R. Satija, "Damping subsynchronous resonance in power system using Static VAR system” Dissertation, University of Delhi, Delhi, India, 2007.

[6] K. R. Padiyar, R. K. Varma, "Static Var System Auxiliary Controllers for Improvement of Dynamic Stability" International Journal of Electrical Power and Energy Systems, vol. 12, pp. 287-297, 1990.
[7] IEEE Subsynchronous Resonance Task Force, "First benchmark model for computer simulation of subsynchronous resonance" IEEE Transactions on Power Apparatus and Systems, vol. 96, pp. 1565-1572, 1977.

[8] V. Jain, N. Kumar, "Designing of supplementary controller for STATCOM for mitigation of subsynchronous resonance in series compensated power system" The Journal of CPRI, vol. 10, pp. 641-652, 2014. 